\title{
A new method for studying platelets, based upon the low-angle light scattering technique. 3. Aggregation hypersensitivity of platelets (ADP agonist) and search for corrective agents
}

\author{
Igor V. Mindukshev ${ }^{a}$, Nikolay V. Goncharov ${ }^{b}$, Elena Yu. Shabanova ${ }^{c}$, Elena E. Ermolaeva ${ }^{b}$, \\ Maria O. Mironova ${ }^{\mathrm{b}}$, Andrey S. Radilov ${ }^{\mathrm{b}}$, Richard O. Jenkins ${ }^{\mathrm{d}, *}$ \\ and Alexander I. Krivchenko ${ }^{\text {a }}$ \\ ${ }^{a}$ I.M. Sechenov Institute of Evolutionary Physiology and Biochemistry, Russian Academy of Sciences, \\ St-Petersburg, Russia \\ ${ }^{\mathrm{b}}$ Research Institute of Hygiene, Occupational Pathology and Human Ecology, St-Petersburg, Russia \\ ${ }^{\mathrm{c}}$ I.P. Pavlov Medical University, St-Petersburg, Russia \\ ${ }^{\mathrm{d}}$ School of Allied Health Sciences, De Montfort University, Leicester, UK
}

\begin{abstract}
A new method for studying platelets based on low-angle light scattering has previously revealed that platelets taken from pregnant women with preeclampsia are hypersensitive to ADP, with aggregation developing at concentrations of 7$15 \mathrm{nmol}^{-1}$. The method has been applied to further studies in experimental toxicology and clinical pathology. Toxicological experiments with fluoroacetate (FA), an inhibitor of TCA cycle, showed that the platelet hypersensitivity could also be caused by energy depletion. In modeling experiments, the low-angle light scattering method was applied to assessment of potential corrective agents of the pathological states related to hypersensitivity of platelets. Sodium glutamate (SG) was shown to be a potent antiaggregant in vitro, and subsequent in vivo studies demonstrated that SG can apparently serve as anaplerotic agent and normalize the platelet status of rats intoxicated with FA. Donators of nitric oxide (NO), such as isosorbide- $5^{\prime}$-dinitrate, can also normalize in vitro the hypersensitive status of platelets taken from the patients with preeclampsia.
\end{abstract}

Keywords: Platelets, aggregation, light scattering, fluoroacetate, preeclampsia

\section{Introduction}

Previously we have shown, using a low-angle light scattering method, that there is a certain order of ADP concentrations acting on three types of purine receptors, $\mathrm{EC}_{50} \sim 20 \mathrm{nmoll}^{-1}\left(\mathrm{P}_{2} \mathrm{X}_{1}\right)<$ $\mathrm{EC}_{50} \sim 90 \mathrm{nmoll}^{-1}\left(\mathrm{P}_{2} \mathrm{Y}_{1}\right)<\mathrm{EC}_{50} \sim 120 \mathrm{nmol}^{-1}\left(\mathrm{P}_{2} \mathrm{Y}_{12}\right)$ [1]; $\mathrm{EC}_{50}$ of ADP reflecting the sensitivity of $\mathrm{P}_{2}$ receptors for this purine. Platelets normally are activated with $\mathrm{P}_{2} \mathrm{X}_{1}$ receptor, $\mathrm{EC}_{50}$ being in the

\footnotetext{
${ }^{*}$ Corresponding author: R.O. Jenkins, School of Allied Health Sciences, De Montfort University, Leicester, LE1 9BH, UK. Tel.: +44 116 2506306; E-mail: roj@dmu.ac.uk.
} 
range of 5-30 nmol $\mathrm{n}^{-1}$. It was also shown that $\mathrm{P}_{2} \mathrm{X}_{1}$ receptors play an important role in increase of intracellular concentration of $\mathrm{Ca}^{2+}$ and in transition of platelets to a spherical state [2]. $\mathrm{P}_{2} \mathrm{X}_{1}$ receptors also play a regulatory role in hemostasis and thrombosis in vivo [3]. Normally, aggregation is induced with cooperative participation of $\mathrm{P}_{2} \mathrm{Y}_{1}$ and $\mathrm{P}_{2} \mathrm{Y}_{12}$ receptors, with ADP in the range 110-160 nmol $\mathrm{l}^{-1}$ [1]. At the same time, in studies of functional activity of platelets from pregnant women with preeclampsia we revealed a hypersensitivity of platelets, with aggregation being developed at ADP concentrations of 7-15 nmol $1^{-1}$ and $\mathrm{P}_{2} \mathrm{X}_{1}$ receptors being cooperatively bound with ADP [4]. An unsolved problem is that of the role of two other groups of $\mathrm{P}_{2}$ receptors coupled with G-proteins in the development of hypersensitivity of platelets. This problem is closely related with another one, namely reciprocal relations of intracellular energetics and signalling pathways. ATP is needed for Ca-ATPases to control the intracellular calcium balance, and GTP is needed for G-proteins and related receptors.

In the present work, we tried to find an approach to these problems with the low-angle light scattering technique, having conducted additional clinical and laboratory experiments with platelets obtained from patients with preeclampsia, as well as toxicological experiments with fluoroacetate (FA), an inhibitor of TCA cycle. Our choice of FA for modeling the hypersensitivity was reasoned by common disturbances of hemodynamics and $\mathrm{Ca}^{2+}$ balance in development of the two intoxications, in spite of radical differences in etiology. During preeclampsia, disorders of microcirculation cause (or are caused by?) a number of essential shifts in metabolism. Intracellular phospholipases are activated, generating toxic radicals that break the barrier and matrix functions of cell membranes. As a consequence, ionic channels and primarily calcium channels become dysfunctional, leading to energy starvation and vasospasm [5-7]. Among the physiological and biochemical effects caused by FA, the principal ones are considered to be a reduced level of ATP, disturbance of calcium balance, and acid-base and hemodynamical disorders [8]. In the modeling experiments we tried to find the ways of correction of these pathological states related to hypersensitivity of platelets, using the new technique.

\section{Materials and methods}

Experiments with sodium fluoroacetate (SFA, synthesized in-house at the Research Institute of Hygiene, Occupational Pathology and Human Ecology), sodium acetate (SA, Merck), sodium glutamate (SG, Sigma), and sodium nitroprusside (SNP, Sigma) were conducted with platelets of male Wistar rats using a low-angle light scattering technique [2]. To estimate the kinetic parameters of platelet aggregation in experiments with SFA in vitro, the platelets were incubated with $0.1-10 \mathrm{mmol}^{-1}$ SFA for 1-5 min. In the in vivo experiments, SFA was administered subcutaneously at a dose of $3 \mathrm{mg} \mathrm{kg}^{-1}$. ADP was used as agonist, causing platelet activation and aggregation in the concentration range $10 \mathrm{nmol}^{-1}$ to $10 \mu \mathrm{moll}^{-1}$.

Studies on effects of NO-donators, isosorbide-5-dinitrate and isosorbide-5'-mononitrate (correspondingly IDN and IMN), on the hypersensitive status of platelets were carried out with platelets obtained from pregnant women with preeclampsia $(n=25)$, the level of gravity of the condition was estimated to be nephropathy I. The blood was taken from cubital vein with citrate as anticoagulant. The blood was divided into three $5 \mathrm{ml}$ aliquots: one control and two experimental samples. Isoket ${ }^{\circledR}(0.1 \%$ solution of IDN) or IMN (Sigma) were added to the experimental samples of blood to $120 \mu \mathrm{mol}^{-1}$. Platelet rich plasma (PRP) was then obtained by centrifugation of the samples of blood for $7 \mathrm{~min}$ at $200 \mathrm{~g}$. The total incubation time of IDN or IMN with platelets was $20 \mathrm{~min}$, before registration of light scattering intensity began. 


\section{Results and discussion}

\subsection{Effects of FA on the functional state of platelets}

The mechanism of toxic action of FA is widely known as "lethal synthesis" [9], which essentially involves enzymatic conversion of the inherently nontoxic FA into toxic fluorocitrate (FC). The latter has long been believed to inhibit aconitase, thus blocking the TCA cycle [10,11]. It was discovered later that the actual toxicant is 4-hydroxy-trans-aconitate, a fluorine-free fluorocitrate derivative [12], and FC was named a "suicide substrate" [13]. The physiological and biochemical basis of the toxic action of FA is a disturbance of energetic metabolism, the essence of which is inhibition of substrate oxidation in the TCA cycle, and reduced glycolysis and oxidative phosphorylation. Exogenous FC has been shown to cause a decrease in calcium capacity of mitochondria and to induce a spontaneous leakage of $\mathrm{Ca}^{2+}$ from mitochondria via an electrogenic system and electroneutral $2 \mathrm{H}^{+} / \mathrm{Ca}^{2+}$ exchange [14], as well as a reduction of affinity of G-protein dependent PAF-receptors [15]. We suggested that the effects observed were caused by uncoupling of intracellular regulatory processes due to reduction of ATP level and intensity of substrate phosphorylation with GTP synthesis in the 2-oxoglutarate dehydrogenase complex.

Upon introduction of SFA solution into the cuvette with the platelet suspension, a rapid and apparent activation of platelets was registered. Figure 1 shows the test record with activation of the cells after introduction of $5 \mathrm{mmol}^{-1}$ SFA. For comparison, activation of platelets under action of SA in the same concentration is also shown. After activation of platelets with SFA or SA, aggregation of platelets was initiated with appropriate concentrations of ADP from 10 to $100 \mathrm{nmoll}^{-1}$ (Fig. 2).

On the basis of light scattering intensity (LSI) recordings of platelets exposed to SFA or SA followed by ADP action, plots of dependences of aggregation velocities upon ADP concentrations were obtained (Fig. 3). Having investigated the mode of response of the platelets incubated with SFA at $10 \mathrm{mmoll}^{-1}$,

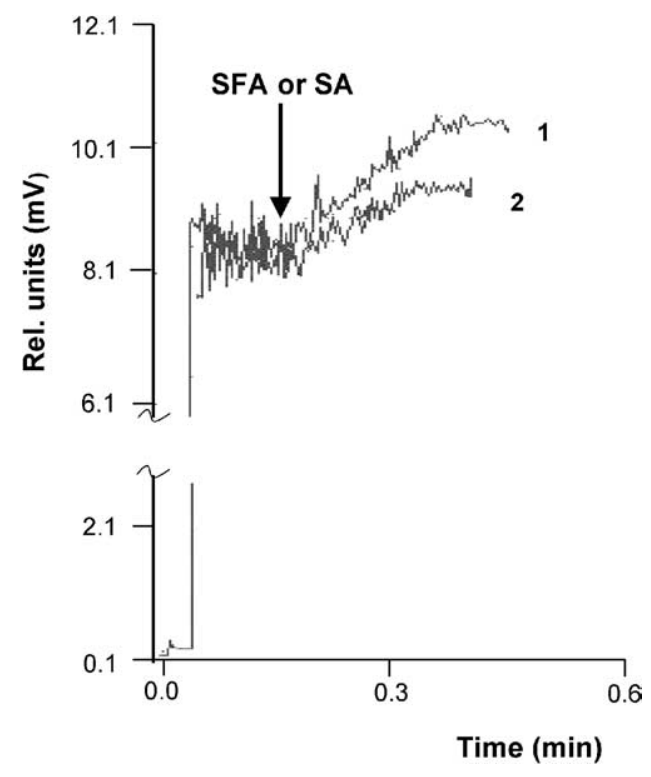

Fig. 1. Registration of light scattering intensity by rat platelets at an angle of 12 degrees $\left(\mathrm{I}^{12}\right)$ induced by action of sodium fluoroacetate (1) or sodium acetate (2), at a concentration of $5 \mathrm{mmoll}^{-1}$. 


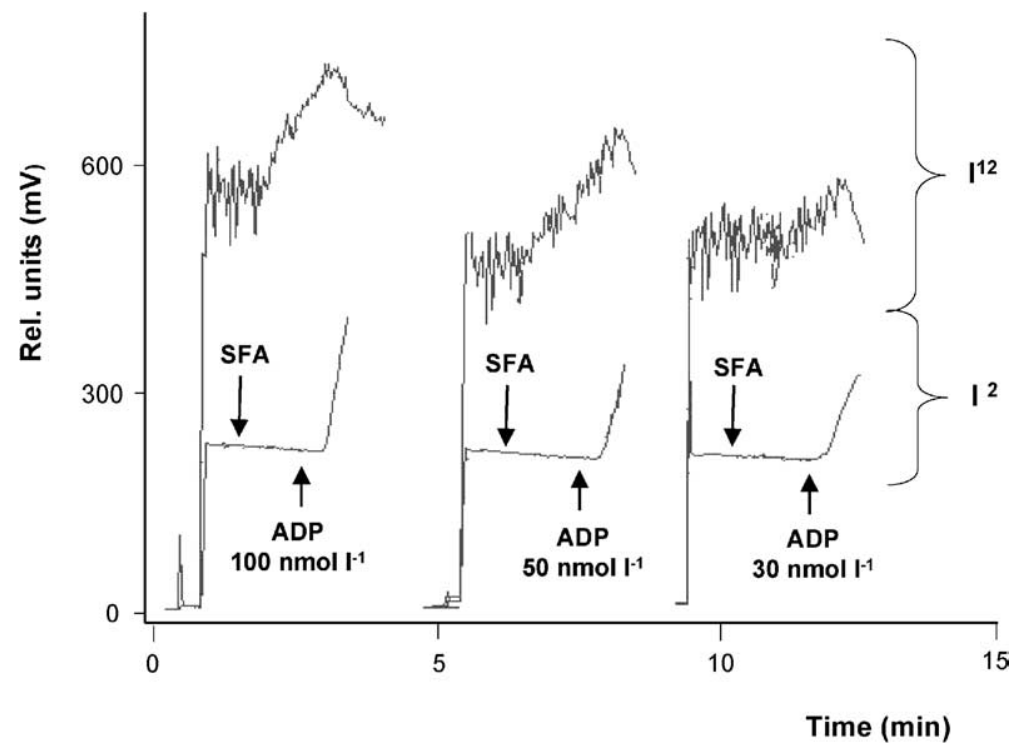

Fig. 2. Registration of light scattering intensity (LSI) by rat platelets under action of sodium fluoroacetate (SFA) at $10 \mathrm{mmoll}^{-1}$, with aggregation induced with ADP over the concentration range 30 to $100 \mathrm{nmoll}^{-1}$. LSI recorded at angles of $2\left(\mathrm{I}^{2}\right)$ and 12 $\left(\mathrm{I}^{12}\right)$ degrees, reflecting the processes of platelet aggregation and platelet activation, respectively.

A

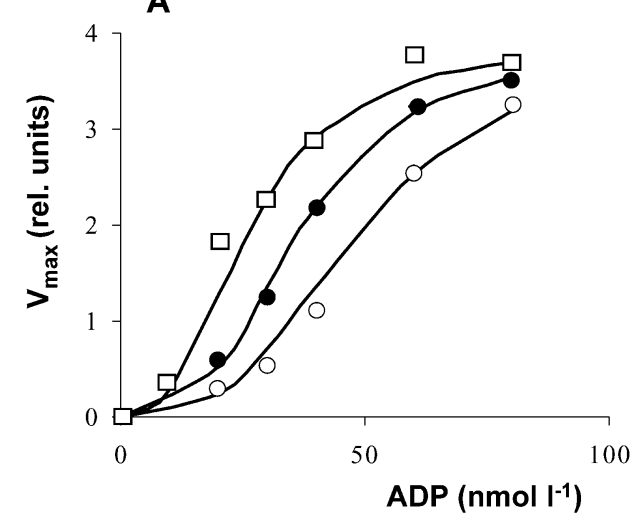

B

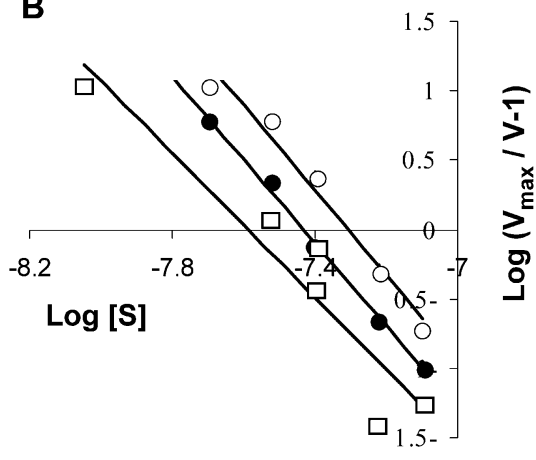

Fig. 3. Dependence of the aggregation velocity of rat platelets upon ADP concentration, and influence of sodium fluoroacetate (SFA) and sodium acetate (SA). (A) dependence of ADP concentration of maximum velocity of aggregation, $V_{\max }$ (unnormalized relative units). (B) the Hill's plot; dependence of $\log \left(V_{\max } / V-1\right)$ upon $\log$ [S], where $\mathrm{S}=\mathrm{ADP}$. SA at $5 \mathrm{mmol} 1^{-1}(\mathrm{O})$; SFA at $5(\bullet)$ and $10 \mathrm{mmoll}^{-1}(\square)$.

the following parameters of their functional activity were obtained: $\mathrm{EC}_{50}=25.24 \pm 8.34$ and $h=2.93 \pm$ 0.62. SFA at $5 \mathrm{mmol}^{-1}$ produced the following levels of kinetic indices: $\mathrm{EC}_{50}=35.13 \pm 12.55$ and $h=$ $3.01 \pm 0.96$. For comparison, the platelets were exposed to $\mathrm{SA}$ at the same concentration $\left(5 \mathrm{mmol} \mathrm{l}^{-1}\right)$ to demonstrate the specific effect of SFA, resulting in $\mathrm{EC}_{50}=53.83 \pm 12.74$ and $h=2.96 \pm 0.79$. The parameter $\mathrm{EC}_{50}$ characterizes the status of platelets exposed to SFA as hypersensitive to ADP, while the coefficient of Hill $(h)$ and dependence of aggregation velocities upon ADP concentrations is evidence of cooperative binding of purine receptors with ADP. 


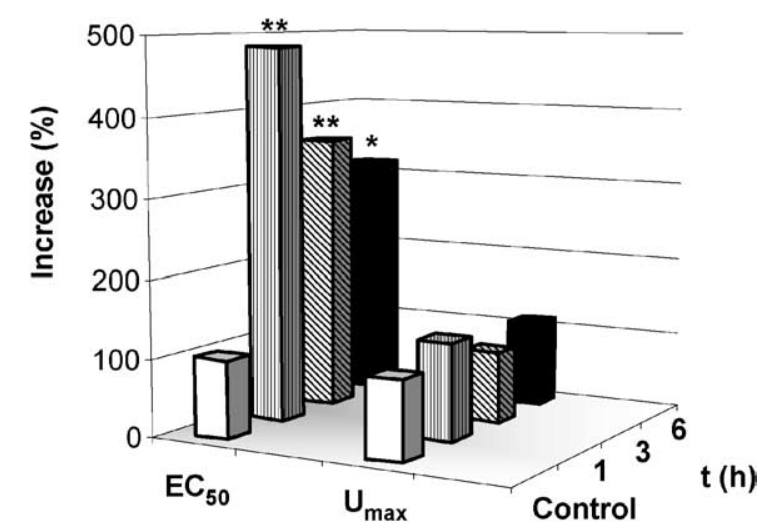

Fig. 4. Changes in kinetic parameters of rat platelet aggregation under intoxication with SFA at $1 / 2 \mathrm{LD}_{50}$. Time of exposure $(t)$ of platelets to SFA ranged from 1 to 6 hours; $U_{\max }=$ maximum velocity of platelet aggregation; ${ }^{*} P \leqslant 0.05$ and ${ }^{* *} P \leqslant 0.01$ relative to Control.

In the in vivo experiments, we studied the kinetic parameters of rat platelet aggregation 1,3 and $6 \mathrm{~h}$ after subcutaneous (s.c.) introduction of SFA at dose $1 / 2 \mathrm{LD}_{50}$. PRP of the poisoned animals was characterized by development of spontaneous aggregation (though being in mixture with citrate as anticoagulant), and this fact was in accordance with our in vitro data on transition of platelets to the hypersensitive status upon action of SFA. However, the cells which avoided aggregation showed an extremely high level of desensitization as a consequence of their transition to the refractory state described in [4]. This is evidenced by increase of their $\mathrm{EC}_{50}$ indices (Fig. 4). In several experiments the development of the refractory state was so intense that ADP could not induce platelet aggregation at a very high (and non-physiological) concentration of $10 \mathrm{mmoll}^{-1}$ (Fig. 6B). The maximal velocity of aggregation having been slightly enhanced $1 \mathrm{~h}$ after the poisoning then reduced by the 3 hour point.

\subsection{Effects of sodium glutamate ( $S G)$ on ADP-induced platelet aggregation and correction of the functional status of platelets in rats poisoned with SFA}

The choice of SG as a potential corrective agent of kinetic parameters of platelet aggregation was based on data on possible utilization of glutamate as an alternative metabolic substrate upon blockade of TCA cycle with fluoroacetate $[16,17]$.

Incubation of platelets for 1 min with SG $\left(0.5-6 \mathrm{mmol}^{-1}\right)$ caused a decrease of intensity of light scattering proportional to concentration of SG, under action of a constant concentration of $1 \mu \mathrm{moll}^{-1}$ ADP (Fig. 5). The minimal significant concentration of SG influencing the initial velocity of platelet aggregation in vitro was calculated to be $5.32 \mathrm{mmol}^{-1}$. In a subsequent series of in vitro experiments, we studied the kinetic parameters of platelets aggregation under the action of SG in concentration close to that calculated as the minimal significant, $6 \mathrm{mmol}^{-1}$ (Table 1). $\mathrm{EC}_{50}$ was enhanced nearly 3 -fold and the maximum velocity of platelet aggregation $\left(U_{\max }\right)$ was reduced nearly 9 -fold. Thus, $\mathrm{SG}$ appeared to be a rather potent antiaggregant in vitro.

To establish whether or not SG could correct the kinetic parameters of rat platelet aggregation in vivo, SG was administered to rats after poisoning with SFA. The rats were administered SFA s.c. at the $\mathrm{LD}_{50}$ dose $\left(3 \mathrm{mg} \mathrm{kg}^{-1}\right)$ and immediately afterwards SG was introduced intraperitoneally at a dose of $250 \mathrm{mg} \mathrm{kg}{ }^{-1}$. After $1 \mathrm{~h}$ of SG administration, PRP was obtained for determination of kinetic parameters of platelet aggregation. Figure 6 shows typical traces registered with platelets from three animals: 


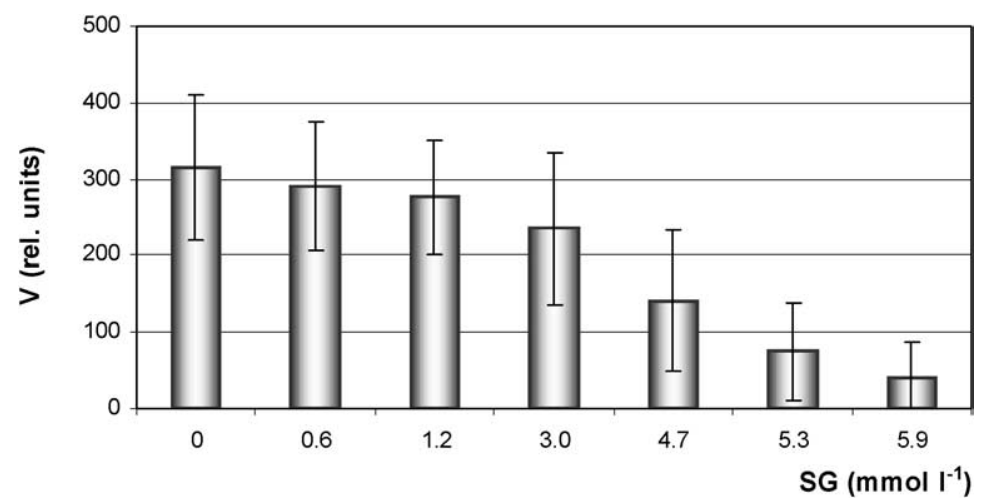

Fig. 5. Initial velocities $(V)$ of rat platelet aggregation after one minute exposure to sodium glutamate (SG) over the range 0.5 to $6.0 \mathrm{mmoll}^{-1}$. Activation of platelet aggregation was with ADP at $1 \mu \mathrm{moll}^{-1}$.

Table 1

Kinetic parameters of rat platelet aggregation after in vitro exposure to SG

\begin{tabular}{|c|c|c|}
\hline Group & $\begin{array}{c}\mathrm{EC}_{50} \text { for ADP } \\
\left(\mathrm{nmol}^{-1}\right)\end{array}$ & $\begin{array}{c}U_{\max } \\
\text { (rel. units) }\end{array}$ \\
\hline Control $(n=9)$ & $284.70 \pm 68.53$ & $189.16 \pm 45.48$ \\
\hline $\operatorname{SG}\left(6 \mathrm{mmol}^{-1}\right)(n=4)$ & $951.6 \pm 209.2$ & $22.2 \pm 49.0^{* *}$ \\
\hline
\end{tabular}

$\overline{U_{\max }}=$ maximum velocity of platelet aggregation; $\mathrm{SG}=$ sodium glutamate; ${ }^{* *} P \leqslant 0.01$ relative to control.

Table 2

Correction with SG of kinetic parameters of rat platelets under intoxication with SFA

\begin{tabular}{|c|c|c|}
\hline \multirow[t]{2}{*}{ Group } & \multicolumn{2}{|c|}{ Parameters of platelet aggregation } \\
\hline & $\begin{array}{l}\mathrm{EC}_{50} \text { for ADP } \\
\left(\mathrm{nmoll}^{-1}\right)\end{array}$ & $\begin{array}{l}U_{\max } \\
\text { (rel. units) }\end{array}$ \\
\hline Control $(n=10)$ & $284.70 \pm 68.53$ & $189.16 \pm 45.48$ \\
\hline $\begin{array}{l}\text { SFA, } \mathrm{LD}_{50} \\
\quad 1 \mathrm{~h} \text { after poisoning }(n=5)\end{array}$ & $1389.4 \pm 441.7^{*}$ & $596.5 \pm 10.3^{*}$ \\
\hline $\begin{array}{l}\text { SFA, } \mathrm{LD}_{50}, \\
\quad+\mathrm{SG} 250 \mathrm{mg} \mathrm{kg}^{-1}, \\
\quad 1 \mathrm{~h} \text { after poisoning }(n=5)\end{array}$ & $294.94 \pm 71.29$ & $280.18 \pm 67.72$ \\
\hline
\end{tabular}

A - control, B - $1 \mathrm{~h}$ after poisoning with SFA, and C $-1 \mathrm{~h}$ after poisoning with SFA and treatment with SG. It can be seen from the traces that SFA does not affect the platelet activation, but causes platelets to become refractory, apparently as a result of their initial hypersensitivity. SG makes the platelets resistant to SFA action, their status being retained at the control level. Calculation of the kinetic parameters proved SG to be a powerful anaplerotic (compensatory) source under the TCA cycle blockade (Table 2). Obviously ATP generation in platelets renders Ca-ATPases functioning to prevent development of hypersensitivity, while GTP generation provides normal functioning of the G-protein mediated signalling pathways, thus safeguarding the adequate response of platelets to physiological concentrations of ADP. 


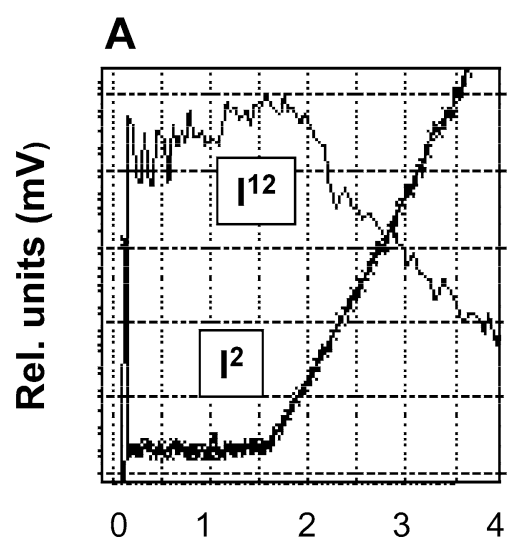

B

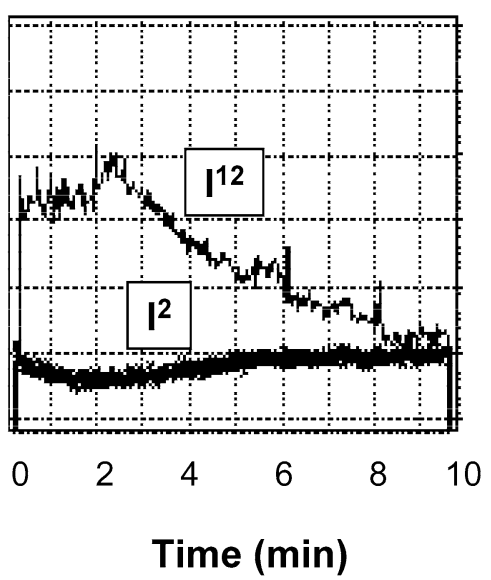

C

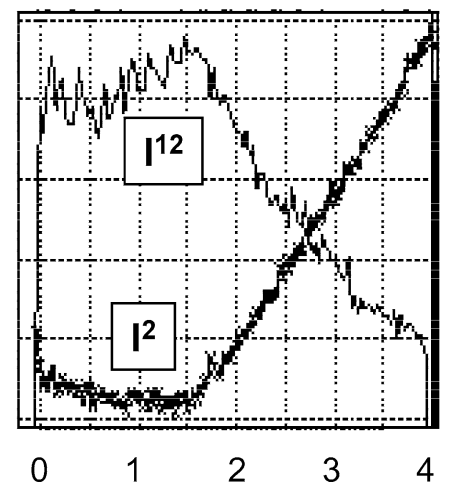

Fig. 6. Influence of sodium fluoroacetate (SFA) and sodium glutamate (SG) on ADP induced activation and aggregation of rat platelets. Light scattering intensity was recorded at angles of 2 and 12 degrees, $\left(\mathrm{I}^{2}\right)$ and $\left(\mathrm{I}^{12}\right)$ respectively. (A) platelets from control rats (under action of $1 \mu \mathrm{mol}^{-1} \mathrm{ADP}$ ); (B) platelets from rats $1 \mathrm{~h}$ after poisoning with SFA (under action of $10 \mu \mathrm{moll}^{-1} \mathrm{ADP}$ ); (C) platelets from rats $1 \mathrm{~h}$ after poisoning with SFA and concurrent treatment with SG (under action of $\left.1 \mu \mathrm{mol} 1^{-1} \mathrm{ADP}\right)$.

\subsection{Effects of sodium nitroprusside (SNP) on ADP-induced aggregation of rat platelets in vitro and correction of the hypersensitive status of platelets obtained from pregnant women with preeclampsia}

We have previously demonstrated that platelets of pregnant women with preeclampsia are characterized by a hypersensitive status with positive cooperative effect of binding ADP with purine receptors [4]. Molecular mechanisms of development of the platelet hypersensitivity are not known at present. Our experiments with SFA suggest that a partial energetic blockade could be a possible mechanism. ATP shortage can lead to decrease in activity of Ca-ATPases, which enhances $\left[\mathrm{Ca}^{2+}\right]_{\mathrm{i}}$ levels. It is clear that pharmacological intervention is needed to correct the hypersensitive status of platelets. As previously shown, nitric oxide (NO) plays an important role in pathogenesis of gestosis $[18,19]$. Significant reduction of aggregating capacity of platelets under treatment with organic nitrates has been reported [20]. Compounds such as SNP, glycerol trinitrate, IDN etc. are potent vasodilators; they also inhibit cell adhesion, activation and aggregation.

To study the effects of SNP on platelets in vitro, platelet aggregation was induced with $400 \mathrm{nmol}^{-1}$ ADP. SNP was then introduced at the peak of ADP-induced aggregation. If aggregation was reversible, SNP would cause development of platelet disaggregation depending upon dose (SNP at concentrations of 50, 100, and $150 \mu \mathrm{moll}^{-1}$ was used, Fig. 7). From the data obtained, the temporal constant $\left(k, \min ^{-1}\right)$ and the half-development period $\left(t_{1 / 2}, \mathrm{~min}\right)$ of the platelet disaggregation process were calculated according to equations: $k=\ln (\Delta I / \Delta T)$ and $t_{1 / 2}=\ln 2 / k$, where $\Delta I$ is a change of disaggregation velocity for the time interval $\Delta T$. The control platelets showed $k \sim 0.0028 \mathrm{~min}^{-1}, t_{1 / 2} \sim 4.12 \mathrm{~min}$; when SNP at $50 \mu \mathrm{moll}^{-1}$ was introduced, the parameters were $k \sim 0.0037 \mathrm{~min}^{-1}, t_{1 / 2} \sim 3.12 \mathrm{~min}$; SNP at $100 \mu \mathrm{moll}^{-1}$ gave $k \sim 0.0044 \mathrm{~min}^{-1}, t_{1 / 2} \sim 2.62 \mathrm{~min}$, and SNP $150 \mu \mathrm{moll}^{-1}$ showed $k \sim 0.006 \mathrm{~min}^{-1}, t_{1 / 2} \sim 1.92 \mathrm{~min}$. The control platelets without addition of SNP developed a disaggregation, the velocity of which increased up to $4 \mathrm{~h}$ after platelets were obtained (aggregation was 
A

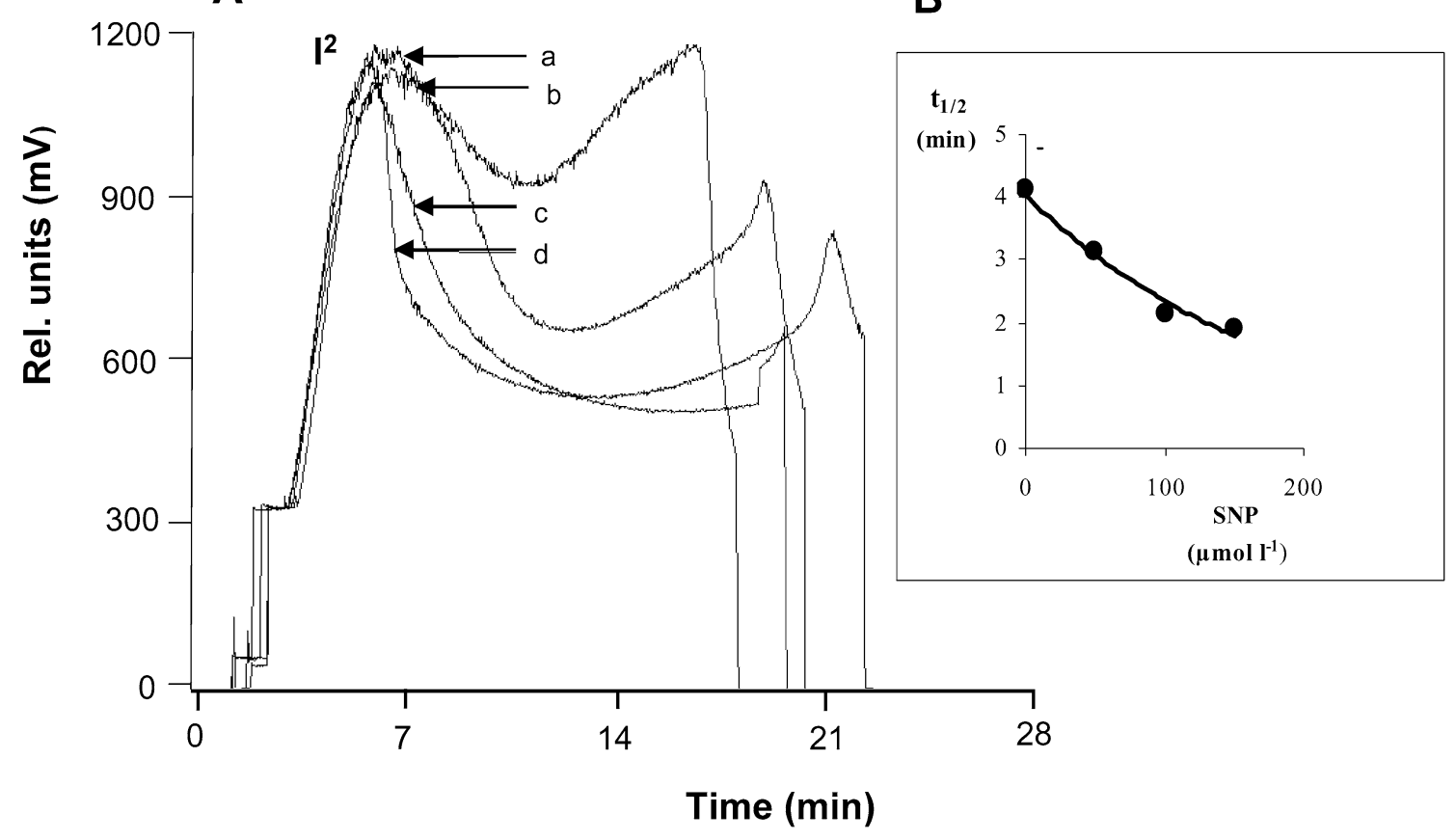

Fig. 7. Dose-effect dependence of rat platelet aggregation upon sodium nitroprusside (SNP) addition. (A) Light scattering intensity recorded at an angle of 2 degrees $\left(\mathrm{I}^{2}\right)$ at different SNP concentrations $\left(\mu\right.$ moll $\left.^{-1}\right)$ : 0 (control; a); 50 (b); 100 (c); 150 (d). (B) Plot of half-development period $\left(t_{1 / 2}\right)$ of the disaggregation process against SNP concentration.

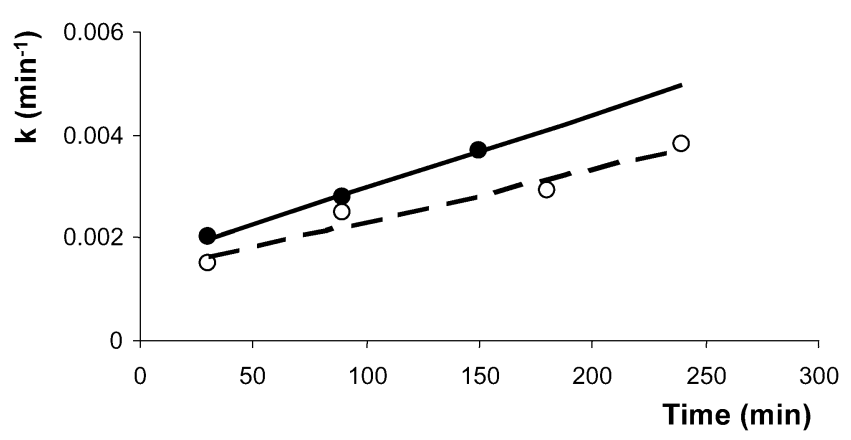

Fig. 8. Dependence of the time constant $(k)$ of rat platelet disaggregation upon time, and effect of sodium nitroprusside (SNP). Aggregation was induced by ADP at $400 \mathrm{nmol}^{-1}$ with measurements taken from the moment of obtaining the platelet rich plasma. Control (O), development of disaggregation; influence of SNP $(\bullet)$ on disaggregation, with $50 \mu$ mol $^{-1}$ SNP introduced at the peak of ADP-induced aggregation.

induced by ADP, $400 \mathrm{nmoll}^{-1}$ ). Addition of SNP at $50 \mu \mathrm{moll}^{-1}$ enhanced disaggregation at the ADPinduced aggregation in a time dependent manner (Fig. 8).

A series of ex vivo experiments was carried out with platelets obtained from patients with preeclampsia. The platelets were incubated with donators of NO (IDN or IMN, $120 \mu \mathrm{mol}^{-1}$ ), then activated with $\mathrm{ADP}$ at concentrations from 2 to $40 \mathrm{nmoll}^{-1}$. The data on the functional parameters $\left(h, \mathrm{EC}_{50}\right)$ of the platelets with and without NO donators are given in Table 3. It is evident that even after incubation of the platelets with NO donators the cooperative effect of ADP binding with purine receptors was observed 
Table 3

Effect of nitric oxide on the kinetic parameters of the hypersensitive platelets obtained from patient with preeclampsia

\begin{tabular}{lcc}
\hline Group & $h$ & $\begin{array}{c}\mathrm{EC}_{50} \text { for ADP } \\
\left(\mathrm{nmol}^{-1}\right)\end{array}$ \\
\hline Control $(n=15)$ & $2.59 \pm 0.55$ & $10.88 \pm 3.69$ \\
IMN $(n=15)$ & $2.06 \pm 0.56$ & $66.12 \pm 18.0^{* * *}$ \\
IDN $(n=15)$ & $1.91 \pm 0.68$ & $52.67 \pm 20.72^{* * *}$ \\
\hline
\end{tabular}

$h=$ Hill's coefficient; IMN $=$ isosorbide- $5^{\prime}$-mononitrate; IDN $=$ isosorbide- $5^{\prime}$-dinitrate; ${ }^{* * *} P \leqslant 0.001$ relative to control.

( $h \sim 2.06$ ). At the same time, a stabilizing effect of the exogenous donators of NO is apparent. It is known that NO causes increase of intracellular cGMP, which induces a decrease of $\left[\mathrm{Ca}^{2+}\right]$ i through activation of cGKI; the final effect of exogenous NO is inhibition of platelet aggregation, phosphorylation of several target proteins such as VASP and thromboxane receptor coupled with Gq-proteins [21-23]. The pathology, which is characterized by the hypersensitivity of platelets to stimuli, is related to a high risk of thrombosis and embolism development and needs to be corrected by administration of corresponding donators of NO.

\section{Conclusions}

The low-angle light scattering technique was successfully applied to investigation of the hypersensitive status of platelets, in in vivo, in vitro or ex vivo studies either of the platelet status per se or potential correctors of the hypersensitive status of platelets. It was shown for the first time that one of the main causes of the hypersensitive status could be a partial or complete blockade of the TCA cycle. Seemingly, the greater the TCA cycle blockade the higher the probability of the refractory state of the platelets being developed, as characterized by an increased $\mathrm{EC}_{50}$ index. It was also shown that the hypersensitive status can be corrected in two fundamentally different ways: (1) effects of NO donators on the cGMPdependent phosphorylation; (2) effects of alternative substrates on activation of alternative metabolic pathways compensating the energetic deficiency of platelets (and other cells?).

\section{Acknowledgement}

This work was partly supported by the BioIndustry Initiative Program of the US Department of State, ISTC grant \#2629.

\section{References}

[1] M.R. Sakaev, I.V. Mindukshev, E.E. Lesiovskaia, N.N. Petrishchev and A.I. Krivchenko, [Efficacy of purine nucleotides on purinergic P2 platelet receptors by small angle light scattering], Eksp. Klin. Farmakol. 63 (2000), $65-69$ [in Russian].

[2] I.V. Mindukshev, I.E. Jahatspanian, N.V. Goncharov, R.O. Jenkins and A.I. Krivchenko, A new method for studying platelets, based upon the low-angle light scattering technique. 1. Theoretical and experimental foundations of the method, Spectroscopy 19 (2005), 235-246.

[3] C. Oury, M.J. Kuijpers, E. Toth-Zsamboki, A. Bonnefoy, S. Danloy, I. Vreys, M.A. Feijge, R. De Vos, J. Vermylen, J.W. Heemskerk and M.F. Hoylaerts, Overexpression of the platelet P2X1 ion channel in transgenic mice generates a novel prothrombotic phenotype, Blood 101 (2003), 3969-3976. 
[4] I.V. Mindukshev, E.E. Ermolaeva, E.V. Vivulanets, E.Yu. Shabanova, N.N. Petrishchev, N.V. Goncharov, R.O. Jenkins and A.I. Krivchenko, A new method for studying platelets, based upon the low-angle light scattering technique. 2. Application of the method in experimental toxicology and clinical pathology, Spectroscopy 19 (2005), 247-257.

[5] M.F. Knapen, T.P. Mulder, I.A. Van Rooij, W.H. Peters and E.A. Steegers, Low whole blood glutathione levels in pregnancies complicated by preeclampsia or the hemolysis, elevated liver enzymes, low platelets syndrome, Obstet. Gynecol. 92 (1998), 1012-1015.

[6] M.T. Raijmakers, P.L. Zusterzeel, E.M. Roes, E.A. Steegers, T.P. Mulder and W.H. Peters, Oxidized and free whole blood thiols in preeclampsia, Obstet. Gynecol. 97 (2001), 272-276.

[7] S.K. Nadar, I. Karalis, E. Al Yemeni, A.D. Blann and G.Y. Lip, Plasma markers of angiogenesis in pregnancy induced hypertension, Thromb. Haemost. 94 (2005), 1071-1076.

[8] N.V. Goncharov, R.O. Jenkins and A.S. Radilov, Toxicology of fluoroacetate: a review, with possible directions for therapy research, J. Appl. Toxicol. 2 (2006), 148-161.

[9] R.A. Peters and R.W. Wakelin, Fluoroacetate poisoning: Comparison of syntetic fluorocitric acid with the enzymically synthesized fluorotricarboxylic acid, Nature 171 (1953), 1111-1112.

[10] J.F. Morrison and R.A. Peters, Biochemistry of fluoroacetate poisoning: the effect of fluorocitrate on purified aconitase, Biochem. J. 58 (1954), 473-479.

[11] R.A. Peters, Some metabolic aspects of fluoroacetate especially related to fluorocitrate, in: Carbon Fluorine Compounds. A Ciba Foundation Symposium, Associated Scientific Pub. Amsterdam, 1972, pp. 55-70.

[12] T.A. Kent, M.H. Emptage, H. Merkle, M.C. Kennedy, H. Beinert and E. Munck, Mossbauer studies of aconitase. Substrate and inhibitor binding, reaction intermediates, and hyperfine interactions of reduced $3 \mathrm{Fe}$ and $4 \mathrm{Fe}$ clusters, J. Biol. Chem. 260 (1985), 6871-6881.

[13] D.D. Clarke, Fluoroacetate and fluorocitrate: mechanism of action, Neurochem. Res. 16 (1991), 1055-1058.

[14] V.V. Teplova, Yu.V. Evtodiyenko, E.I. Kholmukhamedov, N.G. Sergeyenko and N.V. Goncharov, Effect of fluorocitrate on substrate oxidation and $\mathrm{Ca}^{2+}$ transporting systems of rat liver mitochondria, Cytology (SPb) $34(1992), 69-73$ [in Russian].

[15] N.V. Goncharov, L.M. Glashkina, A.V. Kuznetsov and A.S. Radilov, Effects of fluoroacetate on calcium balance and intracellular signalling in platelets, in: Recepton and Intracellular Signalling, Proceedings of International Conference, Pushchino, 16-18 June, 2003, pp. 54-56 [in Russian].

[16] H.L. Yu, R. Giammarco, M.B. Goldstein, D.J. Stinebaugh and M.L. Halperin, Stimulation of ammonia production and excretion in the rabbit by inorganic phosphate: study of control mechanisms, J. Clin. Invest. 58 (1976), 557-564.

[17] C. Liang, Metabolic control of circulation. Effects of iodoacetate and fluoroacetate, J. Clin. Invest. 60 (1977), 61-69.

[18] J. Neri, F. Piccini, M. Marietta, F. Facchinetti and A. Volpe, Platelet responsiveness to L-arginine in hypertensive disorders of pregnancy, Hypertens. Pregnancy 19 (2000), 323-330.

[19] M.G. Signorello, R. Pascale and G. Leoncini, Transport of L-arginine and nitric oxide formation in human platelets, Eur. J. Biochem. 270 (2003), 2005-2012.

[20] P.M. Bath, R. Pathansali, R. Iddenden and F.J. Bath, The effect of transdermal glyceryl trinitrate, a nitric oxide donor, on blood pressure and platelet function in acute stroke, Cerebrovasc. Dis. 11 (2001), 265-272.

[21] E. Butt, K. Abel, M. Krieger, D. Palm, V. Hoppe, J. Hoppe and U. Walter, cAMP- and cGMP-dependent protein kinase phosphorylation sites of the focal adhesion vasodilator stimulated phosphoprotein (VASP) in vitro and in intact human platelets, J. Biol. Chem. 269 (1994), 14509-14517.

[22] M. Eigenthaler, H. Ullrich, J. Geiger, K. Horstrup, P. Honig Liedl, D. Wiebecke and U. Walter, Defective nitrovasodilatorstimulated protein phosphorylation and calcium regulation in cGMP-dependent protein kinase-deficient human platelets of chronic myelocytic leukemia, J. Biol. Chem. 268 (1993), 13526-13531.

[23] G.R. Wang, Y. Zhu, P.V. Halushka, T.M. Lincoln and M.E. Mendelsohn, Mechanism of platelet inhibition by nitric oxide: in vivo phosphorylation of thromboxane receptor by cyclic GMP-dependent protein kinase, Proc. Natl. Acad. Sci. USA 95 (1998), 4888-4893. 


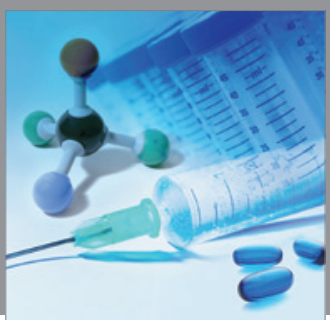

International Journal of

Medicinal Chemistry

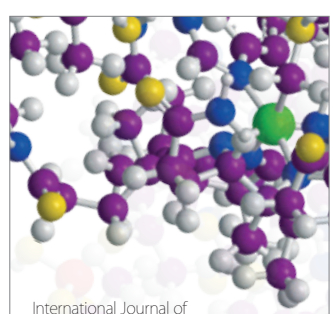

Carbohydrate Chemistry

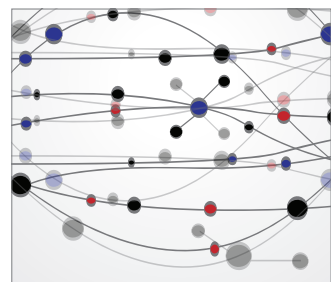

The Scientific World Journal
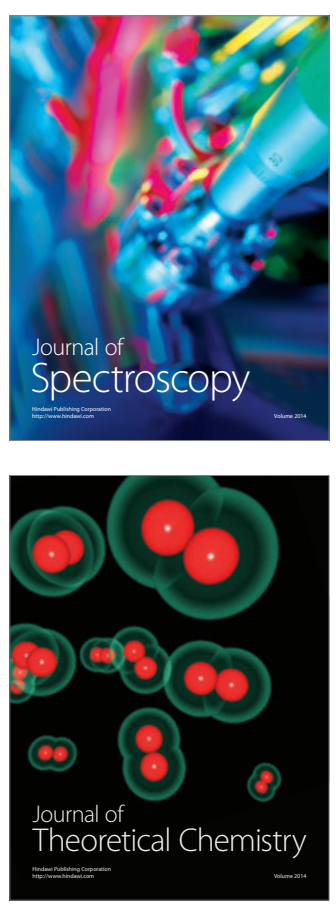
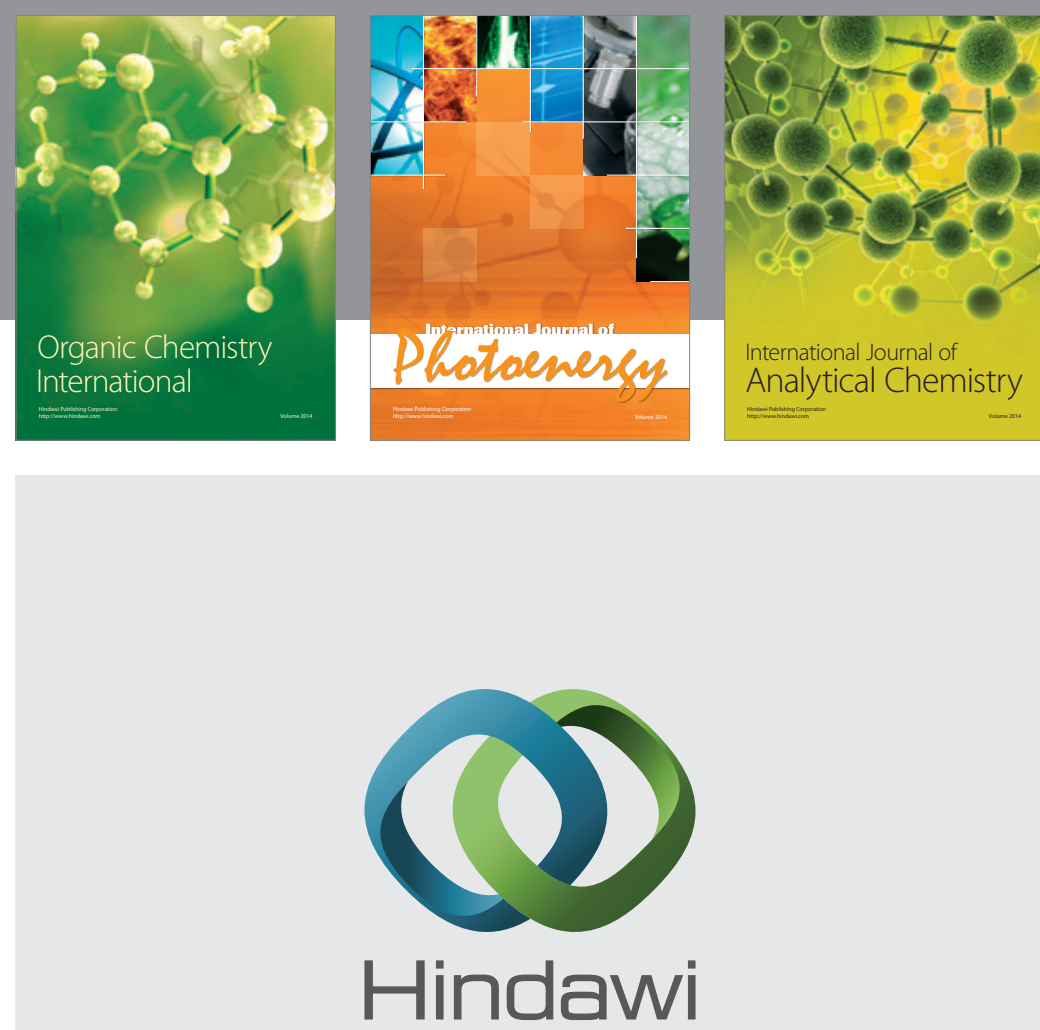

Submit your manuscripts at

http://www.hindawi.com
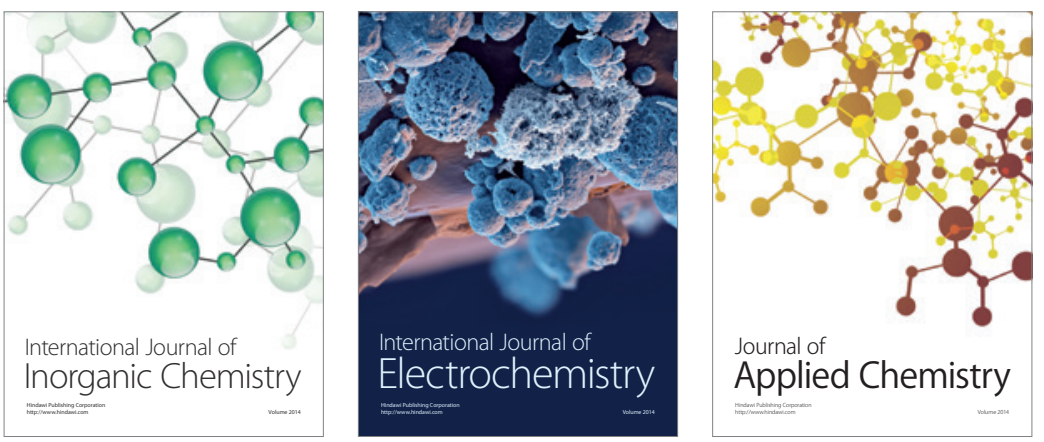

Journal of

Applied Chemistry
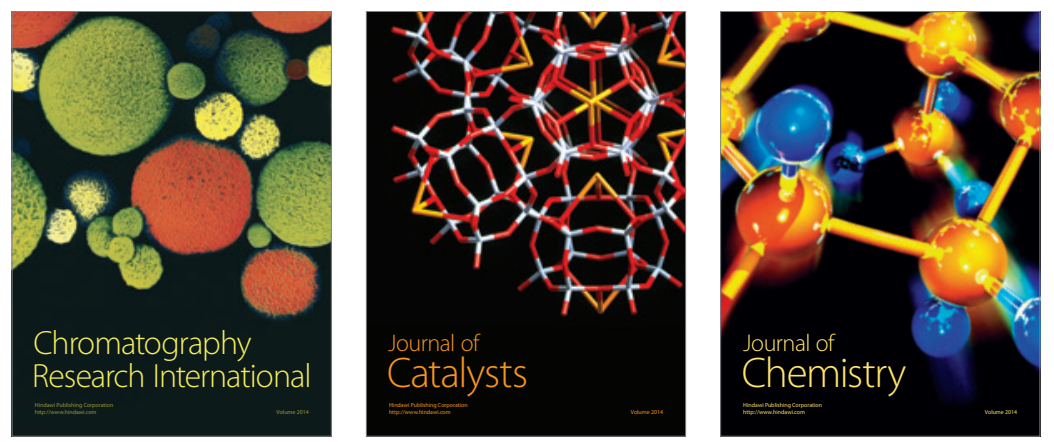
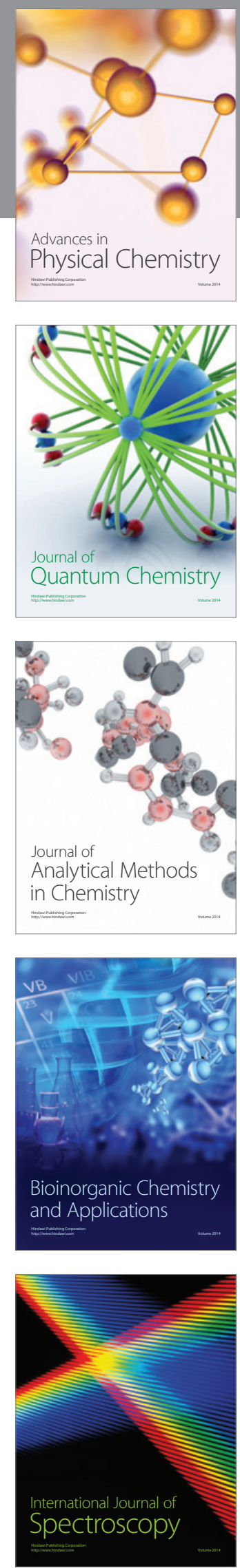